\title{
Mapping forest age using National Forest Inventory, airborne laser scanning, and Sentinel-2 data
}

\author{
Johannes Schumacher ${ }^{*}$ D, Marius Hauglin, Rasmus Astrup and Johannes Breidenbach*
}

\begin{abstract}
Background: The age of forest stands is critical information for forest management and conservation, for example for growth modelling, timing of management activities and harvesting, or decisions about protection areas. However, area-wide information about forest stand age often does not exist. In this study, we developed regression models for large-scale area-wide prediction of age in Norwegian forests. For model development we used more than 4800 plots of the Norwegian National Forest Inventory (NFI) distributed over Norway between latitudes $58^{\circ}$ and $65^{\circ} \mathrm{N}$ in an $18.2 \mathrm{Mha}$ study area. Predictor variables were based on airborne laser scanning (ALS), Sentinel-2, and existing public map data. We performed model validation on an independent data set consisting of 63 spruce stands with known age.

Results: The best modelling strategy was to fit independent linear regression models to each observed site index (SI) level and using a SI prediction map in the application of the models. The most important predictor variable was an upper percentile of the ALS heights, and root mean squared errors (RMSEs) ranged between 3 and 31 years (6\% to $26 \%)$ for Sl-specific models, and 21 years (25\%) on average. Mean deviance (MD) ranged between -1 and 3 years. The models improved with increasing SI and the RMSEs were largest for low SI stands older than 100 years. Using a mapped SI, which is required for practical applications, RMSE and MD on plot level ranged from 19 to 56 years (29\% to 53\%), and 5 to 37 years (5\% to $31 \%$ ), respectively. For the validation stands, the RMSE and MD were $12(22 \%)$ and 2 years (3\%), respectively.

Conclusions: Tree height estimated from airborne laser scanning and predicted site index were the most important variables in the models describing age. Overall, we obtained good results, especially for stands with high SI. The models could be considered for practical applications, although we see considerable potential for improvements if better SI maps were available.
\end{abstract}

Keywords: Forest age, Lidar, Optical satellite images, Remote sensing, Forest inventory

\section{Background}

Forest stand age is a key parameter in designing both forest management and forest conservation strategies. Determining forest age is not a trivial task and can be difficult in a complex forest structure, although it is simpler in more evenaged forests. A description and characterization of the

\footnotetext{
* Correspondence: johannes.schumacher@nibio.no;

johannes.breidenbach@nibio.no

National Forest Inventory, Norwegian Institute of Bioeconomy Research, Ås, Norway
}

different types of forest age can be found in Chirici et al. (2011). Forest age can be determined based on stem cores taken at individual reference trees (Grissino-Mayer 2003). Counting the number of year rings in the stem core exTime since disturbance, which is measurable with remotely sensed time series, could be used to estimate stand age. However, under boreal and temperate conditions where 
rotation periods commonly are longer than $60-80$ years, the application of this method will be limited. Alternative technologies are required to estimate forest stand age for larger areas to be of practical use for forest management and conservation strategies. For example, in Norway the age of stands is often unknown, there are no public maps with reliable estimates of forest age, and even in areas with forest management inventories age is often one of the most uncertain parameters.

Growing processes over time result in specific tree dimensions and forest structure and are determined by a combination of historic management and abiotic factors. Management includes tree species, genetic material, establishment history, stand density, and past harvesting activities. Abiotic factors are environmental conditions including topography, soil type, and macro- and microclimatic variables. These characteristics determine the growth and production potential of a site for a given tree species and result in trees of greatly varying dimensions given the same age. Site index is typically used to describe this productivity and is tree-species specific. Site index is commonly determined by measuring the height and age of dominant trees in even-aged stands found on that site (Skovsgaard and Vanclay 2008). Other methods for estimating site index make use of climate (Nothdurft et al. 2012; Sharma et al. 2012) or remotely sensed data (Socha et al. 2017; Kandare et al. 2017).

Forest stand age and site characteristics described by site index determine the status of forest height, structure and density. Therefore, stand height and structure together with site characteristics can be used to estimate stand age. Proxies for forest stand height and structure can be estimated from remotely sensed data, such as airborne laser scanning (ALS) (Næsset 1997; Nord-Larsen and Riis-Nielsen 2010; Hudak et al. 2014; Mura et al. 2015; Guo et al. 2017) or optical data (Kayitakire et al. 2006; Mora et al. 2013; Lang et al. 2019), which often exist for large areas. In Norway, the site characteristics climate and water and light availability are largely related to geographical location, height above sea level (asl), distance from coast, and terrain slope, which determine temperature, precipitation, water and nutrient availability, and length of growing season (Antón-Fernández et al. 2016).

Previous research demonstrated that forest stand age can be modelled using spectral data (Jensen et al. 1999; Reese et al. 2003; Buddenbaum et al. 2005; Kayitakire et al. 2006; Dye et al. 2012), 3D data from ALS (Maltamo et al. 2009; Racine et al. 2014; Zhang et al. 2014), and a combination of both (Straub and Koch 2011). Kayitakire et al. (2006) used image texture features from IKONOS-2 satellite images with $1 \mathrm{~m} \times 1 \mathrm{~m}$ ground resolution and linear modelling to explain forest stand age and other structure-related variables. Their study site was in Belgium and included 29 sample plots in even aged Norway spruce stands with age between 27 and 110 years. Age was best explained by the correlation texture feature calculated within a $15 \mathrm{~m} \times 15 \mathrm{~m}$ window, resulting in $\mathrm{R}^{2}$ of 0.81 with a mean absolute error of 10 years. Racine et al. (2014) used ALS data and the k-nearest neighbour $(\mathrm{kNN})$ approach to estimate forest stand age based on 158 forest plots in managed boreal forest in central Quebec, Canada. The mean plot age ranged from 11 to 94 years. The best model combining ALS based forest structure variables and ALS based variables describing site characteristics resulted in $\mathrm{R}^{2}$ of 0.83 and root-mean-squared error (RMSE) of 8.8 years. Maltamo et al. (2009) used ALS data and the kmost similar neighbor approach on 335 NFI plots in a 22, 000 ha study site in Finland and reported RMSE of 23.5, 18.8 , and 18.7 years for age of pine, spruce, and deciduous plots, respectively. Straub and Koch (2011) used both airborne ALS and multispectral variables to model forest stand age in a small study area $\left(9.24 \mathrm{~km}^{2}, 108\right.$ forest stands, 300 inventory plots) in south-west Germany using linear regression, reporting RMSE and RMSE\% of 19.7 years and $28.8 \%$, respectively. Buddenbaum et al. (2005) used hyperspectral HyMap data from the spectral angle mapper to classify Norway spruce and Douglas fir age classes on a study site located within one HyMap scene covering $2.5 \mathrm{~km} \times 10 \mathrm{~km}$ in south-west Germany. Their best result of $81 \%$ overall accuracy was achieved with the maximum likelihood classifier for the four age categories $10-30,30-50,50-80$, and $>80$ years. Reese et al. (2003) performed estimation of forest stand age using Landsat 7 satellite data, field data from the Swedish NFI, and the kNN approach in south-western Sweden. In this area, field data for 89 Norway spruce dominated stands ranging from 6 to 106 years were available. RMSE of predicted age for these stands was 12 years or $23 \%$. Maltamo et al. (2020) found that modelling age of stands using ALS for forests older than 100 years was infeasible. For forest stands below 100 years, their model resulted in RMSE of 14 years.

In other studies outside the temperate and boreal zone, Dye et al. (2012) used spectral and texture information from high resolution satellite QuickBird images and random forest to predict the age of pine forests in the west of South Africa. They used 142 sample stands, and age ranged from 4 to 24 years. Their normalized out-of-bag errors ranged from $28 \%$ to $34 \%$. Jensen et al. (1999) modelled coniferous forest age of a small study site in Brazil using Landsat TM satellite data and regression and artificial neural network approaches. Main tree species was loblolly pine and tree age ranged from 1 to 40 years. Percentage of stands with absolute age errors below 2 years were up to $83 \%$ of all stands for multiple regression modelling and up to $98 \%$ of all stands for the best artificial neural network. In a study in central Italy comprising 128,402 ha forest in various growing 
conditions, Frate et al. (2015) used multispectral satellite imagery and 304 field plots to first model timber volume using the $\mathrm{kNN}$ approach, and subsequently used inverted yield models to predict forest age. On 305 independent validation stands covering 3137 ha and stand age from 1 to 127 years with a mean of 52 years, they obtained forest age estimates with RMSE of 16 years (30\%). Zhang et al. (2014) used forest height from spaceborne ALS and non-linear regression modelling to predict forest age in China at $1 \mathrm{~km}$ resolution. The authors fitted first biomass-height and then age-biomass models using field observations from 3543 forest plots, and reported $\mathrm{R}^{2}$ of 0.6 and 0.7 , respectively. However, the spatial resolution was $1 \mathrm{~km}$, which is too coarse for operational forest management. To the best of our knowledge there are no large-scale studies predicting forest stand age that can be used for practical forest management.

The objective of the present study was to model and map forest stand age of Norway spruce (Picea abies (L.) H.Karst.), Scots pine (Pinus sylvestris L.), and broadleaved (mostly downy birch (Betula pubescens Ehrh.)) dominated forest using National Forest Inventory (NFI) sample plots with ALS and optical satellite variables. We validated the results on an independent data set consisting of forest stands with known age. Even though we conducted all analyses for all three tree species, we focus on spruce in the main text and present the results for pine and birch in the Supplementary Information.

\section{Material and methods}

Study area

The 18.2 Mha study area is located in Norway between latitudes $58^{\circ}$ and $65.3^{\circ} \mathrm{N}$ and was determined by the availability of ALS data (Fig. 1). Growing conditions vary considerably with latitude and elevation. The natural tree line is at around $1100 \mathrm{~m}$ asl in southern Norway and around $130 \mathrm{~m}$ asl in the north. Depending on these factors, climate zones range roughly from subarctic in the north and east, oceanic at the coast, and continental in the south-east. Tree species of main economic

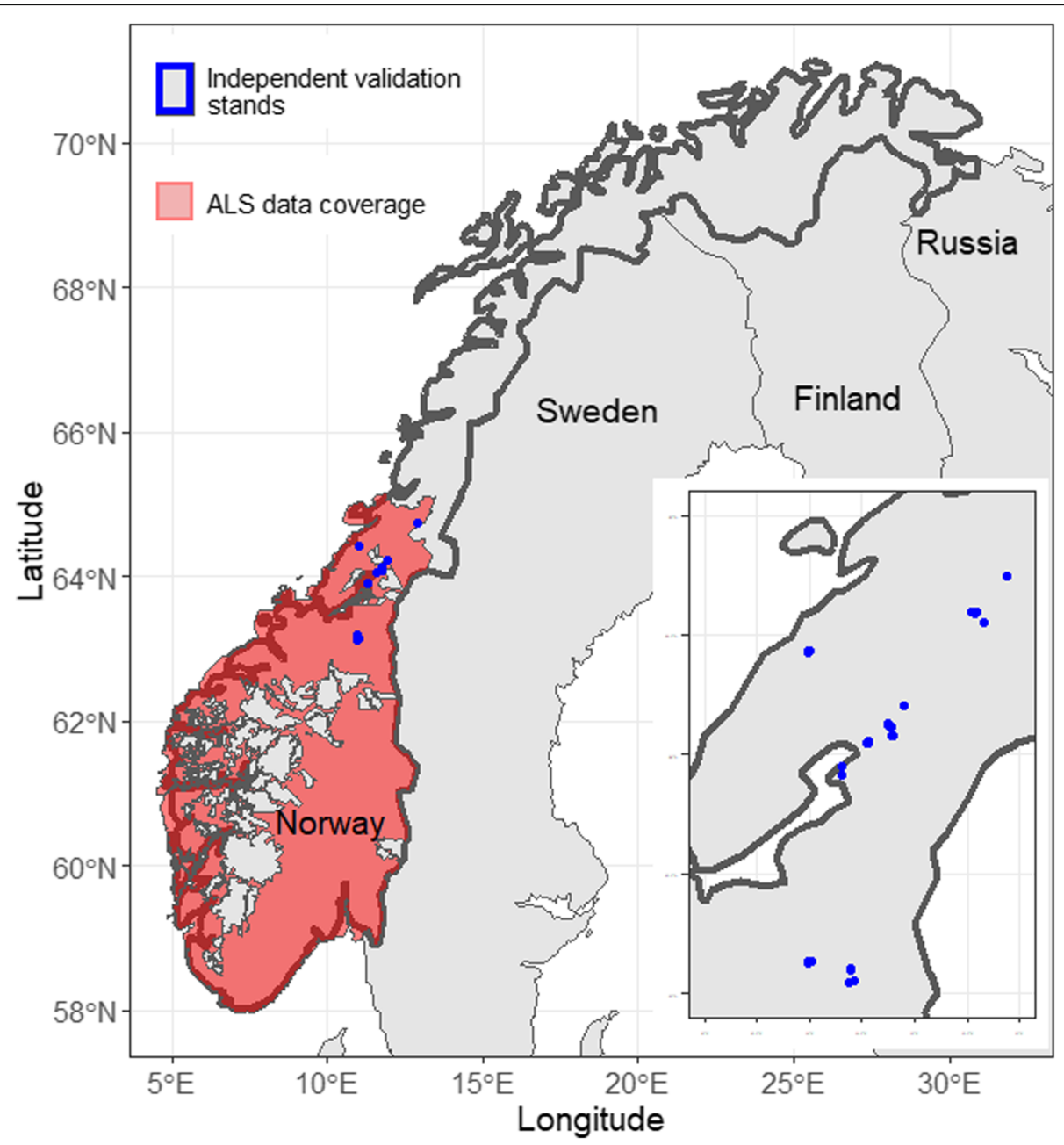

Fig. 1 Map of the study site in Norway; ALS data coverage is displayed in red, and location of independent validation stands in blue 
interest are Norway spruce and Scots pine, making up the majority of biomass and timber volume. Birch is the most abundant species in terms of tree number and mainly occurs as an early succession species after harvests or in high elevation forests.

\section{Data}

\section{National Forest Inventory data}

We used the permanent sample plots of the Norwegian NFI as reference data (Breidenbach et al. 2020a). In the study area, the NFI is based on a systematic grid of 3 $\mathrm{km} \times 3 \mathrm{~km}$ in the lowland region and $3 \mathrm{~km} \times 9 \mathrm{~km}$ in the low-productive, birch-dominated mountain region. For trees with a diameter at breast height $\geq 5 \mathrm{~cm}$ (dbh, $1.3 \mathrm{~m}$ above ground), parameters are measured on circular plots with a size of $250 \mathrm{~m}^{2}$.

Stand parameters such as age and site index are determined on circular sample plots of $1000 \mathrm{~m}^{2}$. Each plot center is permanently marked with a metal pole buried in the ground with known coordinates determined by a global navigation satellite system (GNSS) device. For currently $70 \%$ of the plots within forest, survey-grade differential GNSS measurements are available with an assumed location uncertainty of less than $1 \mathrm{~m}$. For the majority of the remaining plots, the uncertainty is assumed to be less than $5 \mathrm{~m}$. The Norwegian NFI completes one full cycle every five years, i.e. each year one fifth of all plots are visited and forest variables measured. Relevant variables for the present study are stand age, mean height, and site index (SI).

Stand age is determined for each plot from one representative tree just outside the $250 \mathrm{~m}^{2}$-plot boundary by taking a stem core using an increment borer. In multilayered forests, a representative tree per layer is selected. The biological age, rather than chronological age, is recorded that corrects years of suppression below canopy after germination. Alternatively, the number of whorls is counted in young forest where this is possible. In forests that consist of either one or more than two layers, age is the basal-area weighted age of all trees. In two-layered forests, age is the basal-area weighted age of all trees in the dominant layer.

SI is determined in classes of $6,8,11,14,17,20,23$, and 26 which describe the height $(\mathrm{m})$ of the top 100 trees per ha at age 40. To this end, height and age of a tree representative of the 10 largest trees on the 1000 $\mathrm{m}^{2}$ plot are measured and SI is determined based on SI curves (Tveite 1977). For more information on the Norwegian NFI, we refer the reader to Breidenbach et al. (2020a).

We used NFI plots located in stands dominated by spruce, pine, and broadleaved species (defined as plots with $\geq 75 \%$ timber volume of each tree species, respectively). The major tree species in broadleaved dominated forests is downy birch (Betula pubescens Ehrh.), and in the following we only refer to birch when addressing broadleaved dominated forest. From these plots, we only selected NFI plots in productive forest (yearly volume increment $>0.1 \mathrm{~m}^{3} \cdot \mathrm{ha}^{-1}$ ), and removed plots with canopy emergent seed-trees, resulting in 2121 spruce, 1779 pine, and 929 birch dominated plots that were used for modelling. Age for these plots ranged from 3 to 270, 4 to 287 , and 3 to 223 years, respectively (Table 1 ).

\section{Independent validation data}

We used stand-level observations of forest age from 63 forest stands covering a total area of 170 ha as an independent validation data set. The age of these stands was quality-assured by the local forest administration. The stands were located in central Norway in Trøndelag County (Fig. 1) and their age ranged from 11 to 89 years (Table 1). This age range does not cover the full age range in the models. Therefore, we cannot assess the model behavior for forests above 90 years of age with independent data. However, most productive forest is below 100 years of age.

The SI of the stands was reported in another system than for NFI plots and consisted of the three categories "Low", "Medium", and "High". The SI of the stands was, however, not used for predicting stand age.

Table 1 Summary of national forest inventory (NFI) plots and independent validation stands (Val) with known age; characteristics described are number of plots/stands (n), minimum (min), maximum (max), mean, and standard deviation (sd) of age and of mean height, and min, max, and mean of site index (SI), predicted SI (pSI, see next section), and area in hectares (ha)

\begin{tabular}{|c|c|c|c|c|c|c|c|c|c|c|c|c|c|c|c|c|}
\hline & \multirow[b]{2}{*}{$\mathrm{n}$} & \multicolumn{4}{|c|}{ Age (years) } & \multicolumn{4}{|c|}{$\begin{array}{l}\text { 95th percentile of ALS first return heights }(\mathrm{m}) \\
\text { [Field measured arithmetic mean height }(\mathrm{m})]\end{array}$} & \multicolumn{3}{|c|}{ SI (pSI) } & \multicolumn{4}{|c|}{ Area (ha) } \\
\hline & & $\min$ & $\max$ & mean & sd & $\min$ & $\max$ & mean & sd & $\min$ & $\max$ & mean & $\min$ & $\max$ & mean & sum \\
\hline \multicolumn{17}{|l|}{ NFI } \\
\hline Spruce & 2121 & 3 & 270 & 84 & 45 & 0.3 [3.8] & $32.2[33.8]$ & 14.5 [15.3] & $5.3[4.6]$ & $6(8)$ & $26(23)$ & $13(15)$ & 0.025 & 0.025 & 0.025 & 53 \\
\hline Pine & 1779 & 4 & 287 & 106 & 43 & $0.2[5.3]$ & $29.3[28.1]$ & 13.8 [14.2] & $4.0[3.6]$ & $6(8)$ & $23(23)$ & $10(15)$ & 0.025 & 0.025 & 0.025 & 44 \\
\hline Birch & 929 & 3 & 223 & 79 & 33 & 1.0 [4.5] & 27.1 [26.3] & $12.5[11.8]$ & $4.8[4.0]$ & $6(8)$ & $23(23)$ & $11(15)$ & 0.025 & 0.025 & 0.025 & 23 \\
\hline Validation & 63 & 11 & 89 & 53 & 17 & 6.5 & 21.3 & 13.1 & 3.4 & L & M & $\mathrm{H}$ & 0.8 & 10.2 & 2.7 & 170 \\
\hline
\end{tabular}


A total of 62 stands were dominated by spruce, and one stand was dominated by pine according to a tree species map produced independently from this study. The spruce, pine, and birch proportions of the stands according to the species map ranged from $48 \%$ to $100 \%$, from $1 \%$ to $52 \%$, and from $1 \%$ to $39 \%$, respectively. None of the stands were dominated by birch. Therefore, the birch models cannot be evaluated with this independent data set.

\section{Auxiliary data}

Variables extracted from ALS data, a mosaic of atmospherically and topographically corrected Sentinel-2 images, and a raster of the distance to the closest coast line were used for developing models and for mapping age by applying the models. Furthermore, a site index map (pSI), and a tree species map were only used for mapping age by applying the developed models.

Airborne laser scanning data ALS data were collected in several campaigns for the study area, except for high mountain ranges above the tree line. Data were collected between 2010 and 2018 with a density of 2 to 5 pulses per $\mathrm{m}^{2}$, resulting in first return densities ranging between 0.5 and 36 and a mean of 8 first returns per $\mathrm{m}^{2}$. A fine-resolution digital terrain model (DTM, $1 \mathrm{~m} \times 1 \mathrm{~m}$ pixel size) was produced from the last return data by the Norwegian Mapping Authority (Kartverket 2019). The ALS point cloud was height-normalized by subtracting the DTM elevation from corresponding point cloud elevation using bi-directional interpolation. The heightnormalized point cloud was used to calculate various descriptive metrics for each NFI plot based on first returns, first returns above $2 \mathrm{~m}$ height above ground, and last returns. The metrics included mean, variance, coefficients of variation, kurtosis and skewness of ALS return heights, 10th, 25th, 50th, 75th, 90th, and 95th height percentiles, and ALS return density metrics for 10 height slices $(\mathrm{d} 0-\mathrm{d} 9)$. Crown coverage metrics were calculated as percentage of first returns above 2,5 and $10 \mathrm{~m}$. The DTM was resampled to $16 \mathrm{~m} \times 16 \mathrm{~m}$, such that the cell size corresponded approximately to the area covered by an NFI plot $\left(250 \mathrm{~m}^{2}\right)$. From the DTM, terrain slope was computed as a raster with a cell size of $16 \mathrm{~m} \times 16 \mathrm{~m}$. All ALS variables, DTM elevation and slope were extracted for each NFI plot and rasters for those variables with a cell size of $16 \mathrm{~m} \times 16 \mathrm{~m}$ were created for prediction purposes. Furthermore, the time difference between the ALS and the NFI data acquisitions was calculated for each NFI plot.

Sentinel-2 satellite images The two Sentinel-2 (S2) satellites are equipped with multispectral sensors, which detect a broad electromagnetic spectrum $(443 \mathrm{~nm}$ to
$2202 \mathrm{~nm}$ ) in 13 bands. Three of these bands (bands 1, 9, and 10) are measuring atmospheric properties and were not used in this study. S2 bottom of atmosphere (BOA) reflectance images acquired between 30 June and 31 July 2018 were mosaiced using the bands B2, B3, B4, B5, B6, $\mathrm{B} 7, \mathrm{~B} 8, \mathrm{~B} 8 \mathrm{~A}, \mathrm{~B} 11$, and $\mathrm{B} 12$, measuring reflectance in the visible, near infra-red (NIR) and short wave infra-red (SWIR) spectrum (Drusch et al. 2012). The normalized difference vegetation index (NDVI) was calculated as band 8 minus band 4 divided by band 8 plus band 4 . Bands $2-4$ and 8 are acquired with $10 \mathrm{~m}$ spatial resolution, and the bands 5-7, 8A, 11 and 12 with $20 \mathrm{~m}$. The bands in $20 \mathrm{~m}$ resolution were resampled to $10 \mathrm{~m}$ with the nearest neighbor resampling method. To cover entire Norway, 73 S2 scenes were necessary. For each S2 scene, cloud and cloud-shadow areas were masked out and replaced with data from cloudless scenes. The remaining scenes were mosaiced to obtain one mosaic of entire Norway, and color balancing was performed using the PCI Geomatics software (see Puliti et al. (2020) for more information).

S2 variables for each NFI plot were derived by extracting the area-weighted means of the pixel values of each band intersecting with the sample plot polygons. These variables were named corresponding to their S2 band numbers S2_2 through S2_12.

Predicted site index The site index layer of the Norwegian Forest Resource Map SR16 (Astrup et al. 2019) with a 16 $\mathrm{m} \times 16 \mathrm{~m}$ pixel size was used to apply our age models. The (predicted) site index (pSI) was mapped using climate and terrain variables in a boosted regression model utilizing the SI observed on NFI plots as the response (Astrup et al. 2019). Independence of age is crucial for age modelling that utilizes site index as a predictor variable. This was the case for the pSI map which was only based on climate and terrain variables. The pSI map has a resolution of $16 \mathrm{~m} \times 16 \mathrm{~m}$ and is freely available (Norwegian Institute of Bioeconomy Research 2020). Weighted means of the pSI pixels intersecting with the NFI plots were calculated. These weighted means were mapped to the closest SI level (Fig. 2). The RMSE and $\mathrm{MD}$ of the pSI were $3.9(29.7 \%)$ and -2.3 , respectively for spruce, $5.5(54.8 \%)$ and -4.5 , respectively for pine, and 5.1 (45.5\%) and -3.5 , respectively for birch. Clear regression towards the mean effects were visible as the lowest (6) and highest (26) SI levels never occurred in the pSI.

Tree species map The tree species layer (Breidenbach et al. 2020b) of the Norwegian Forest Resource Map SR16 (Astrup et al. 2019) with a $16 \mathrm{~m} \times 16 \mathrm{~m}$ pixel size was used to apply our age models for spruce, pine, and birch pixels. The tree species map was based on multitemporal S2 data and the random forests classifier using NFI plots as a reference. Overall accuracies of this map 

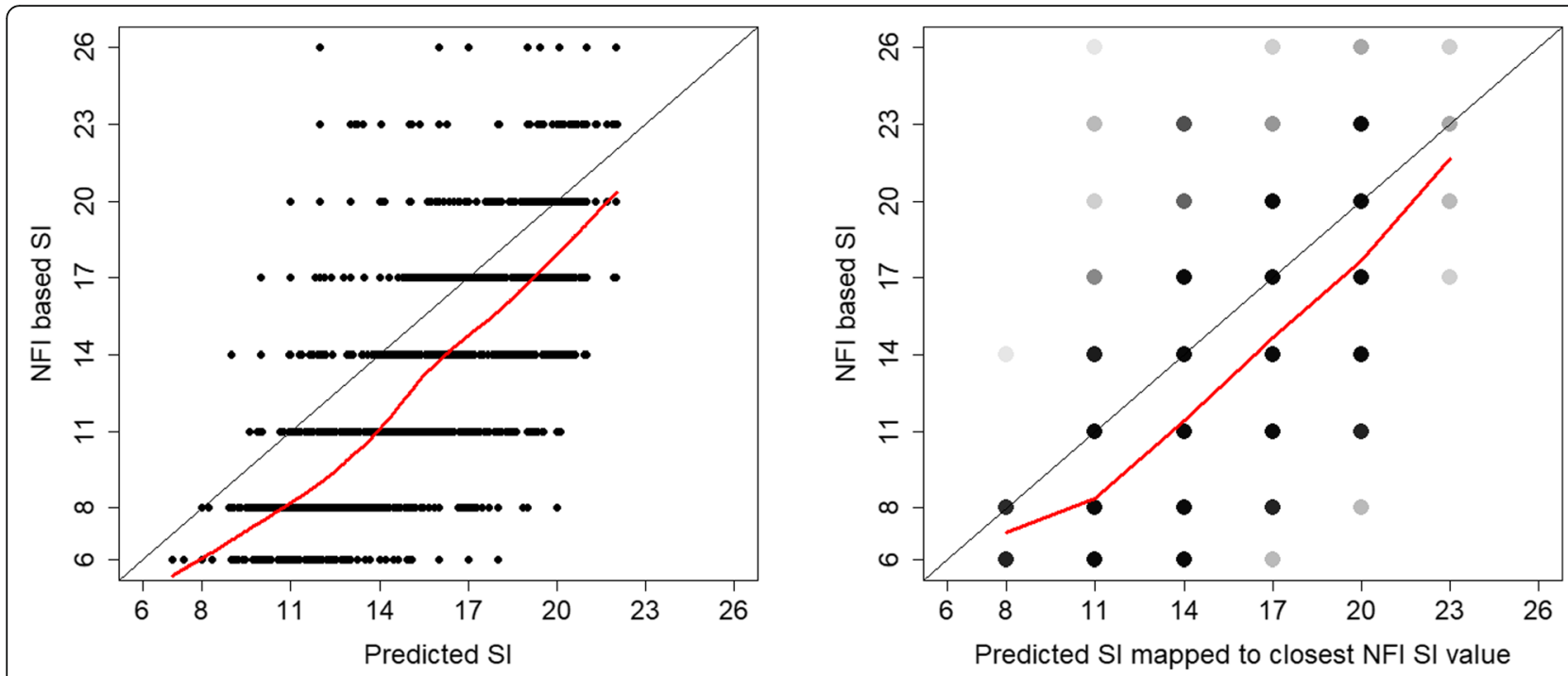

Fig. $2 \mathrm{NFI}$ based site index (SI) vs. predicted SI (pSI) for spruce (plots for pine and birch were similar, and are not shown); left: SI over weighted means of pSI intersecting with NFI plots; right: SI over weighted means of pSI for each NFI plot, mapped to the closest SI level. The darker the color, the more points are over-plotted. The 1:1 line is in grey and a lowess smoothed line is in red

were $75 \%$ on plot level and $90 \%$ on stand level (Breidenbach et al. 2020b). The stand-level user's accuracies for spruce, pine, and birch were $85 \%, 95 \%$, and $88 \%$, respectively.

\section{Methods}

\section{Age modelling}

An area-based approach (Næsset 2002) was utilized to model age observed at NFI plots using remotely sensed variables from ALS and S2 as predictors. Independent linear regression models for each SI were fit with the structure

$$
\boldsymbol{y}=\boldsymbol{X} \hat{\boldsymbol{\beta}}+\boldsymbol{\varepsilon}, \quad \text { with } \boldsymbol{\varepsilon} \sim N\left(\mathbf{0}, \sigma^{2}\right),
$$

where $y=\mathrm{g}($ Age $)$ is the $n$-vector of observed age with $n=$ number of NFI plots and $g$ as a link function, $X=$ design matrix for predictor variables including an intercept, $\hat{\boldsymbol{\beta}}=$ estimated parameters, $\boldsymbol{\varepsilon}=$ independently and normally distributed residuals, and $\sigma^{2}=$ the residual variance. For each SI-specific model, we started with a model including only the 95th percentile of first ALS returns (h95_first) as a proxy for mean height. Final models were fit by forward and backward selection based on Akaike's Information Criterion (AIC) as stopping rule and further selection based on $p$-values $(p<0.05)$. We tested models with the identity (untransformed response variable), square-root, and natural logarithm as the link functions. Based on an initial analysis, the log transformation showed the best results and was chosen for further model development. We corrected for back-transformation bias by adding half the residual variance to the predictions before the back- transformation. Furthermore, we tested if adding predictors such as squared terms, and interactions between predictors, improved the model.

The explanatory variables tree species and site index are observed at the NFI sample plots, but for mapping stand age, the prediction maps as described in Sections 'Tree species map' and 'Predicted site index' have to be used. To analyze the effect of using uncertain explanatory variables on the model accuracy, models based on using the observed and predicted explanatory variables were compared. For the comparison with the validation stands, age was predicted using the predicted explanatory variables, but the model was fit using the observed explanatory variables.

We evaluated the models based on coefficient of determination $\left(R^{2}\right)$, root mean squared error (RMSE), and mean deviance $(\mathrm{MD})$ according to

$$
\begin{aligned}
& \text { RMSE }=\sqrt{\frac{1}{n} \sum_{i=1}^{n} w_{i}\left(y_{i}-\hat{y}_{i}\right)^{2}} \\
& M D=\frac{1}{n} \sum_{i=1}^{n} w_{i}\left(y_{i}-\hat{y}_{i}\right)
\end{aligned}
$$

with $w_{i}=1$. Relative error statistics such as RMSE $\%$ and MD\% were obtained by division by the mean of the observed values and multiplying by 100 .

\section{Validation with independent data}

We evaluated our final models with the independent validation data. We mapped the stand age by applying our regression models according to the mapped tree species 
and pSI to the grid cells with predictor variables on a $16 \mathrm{~m} \times 16 \mathrm{~m}$ raster. Synthetic estimates of stand age were obtained by calculating the mean predicted age for each forest stand. Finally, we compared the estimated stand age with the known age by calculating weighted versions of RMSE, RMSE\%, and MD according to Eqs. 2 and 3, where the weights $w_{i}$ corresponded to the stand area proportion of the $i$ th stand that sum up to 1 and $n=63$. All calculations were performed in $\mathrm{R}$ version 3.6.1 ( $\mathrm{R}$ Core Team 2019).

\section{Results}

\section{Age modelling}

In the following, we will focus on results for spruce. Corresponding results for pine and birch can be found in the Additional file 1. The age-height relationship got stronger with increasing SI for all tree species. More variation was observed for NFI plots in forest stands above 100 years of age, especially for SI levels below 14 .

The strength of the relationship between observed and predicted forest age for the eight SI-specific models increased with increasing SI (Fig. 3. for spruce; for pine and birch see Additional file 1: Figure S1 and Figure S2). A larger variation in the predictions of the models for SI 6 and 8 was clearly visible. For spruce, the adjusted $\mathrm{R}^{2}$ ranged from 0.46 to 0.96 , RMSE from 2.9 to 31.2 years, RMSE\% from $6.4 \%$ to $25.8 \%$, MD from -1.0 to 2.6 years, and MD\% from $-2.2 \%$ to $2.2 \%$ (Table 2). Average RMSE, RMSE\%, $\mathrm{MD}$, and MD\% for all plot classes were 21.2 years, $25.1 \%, 1.0$ years, and $1.2 \%$, respectively (Table 2 ). The results for pine and birch models were worse than for spruce, with $\mathrm{R}^{2}$ ranging from 0.33 to 0.84 for pine and from 0.32 to 0.87 for birch (Additional file 1 : Table S1). For all models, the standard errors were much smaller than their corresponding parameter estimates, and most parameter estimates had $p$-values $<0.001$. The model details for the spruce models can be found in Additional file 1: Table S4 (for pine and birch models Additional file 1: Table S5 and Table S6, respectively).

All models for spruce contained the 95th percentile of the ALS first returns (h95_first) as a predictor variable. The predictor variable h95_first squared (h95_ first2) was included in all models except the one for SI 26, and one of the predictor variables latitude or longitude was included in all models except the models for SI 23 and 26. The models for SI 6, 8, 14, and 17 included at least one of the spectral S2-based variables such as NDVI, S2 band 8A (s2_8A) or 11 (s2_11). The models for SI 11, 14, and 17 contained the largest number of variables with 8,10 , and 8 , respectively (Additional file 1: Table S4). Besides the already mentioned predictors, they also included crown coverage in a height of 2 and $10 \mathrm{~m}$ above ground ( $\mathrm{cc} 2, \mathrm{cc} 10)$, DTM elevation, distance to the coast (distC), terrain slope (slope), and the time difference between field and ALS data acquisition (diffT). The variable h95_first was the most important predictor in all models. This was assessed by refitting the models with standardized predictors. The predictors were centred around their mean, and then scaled by dividing by their standard deviation. The parameter estimates of the centred and scaled version of h95_first were the largest in all models.

We assessed the model behaviour by applying the models to data where the variable h95_first ranged from 0 to the maximum observed value of this variable and all other variables were set to their mean values (Fig. 4, for pine and birch see Additional file 1: Figure S3 and Figure S4). Below a h95_first of $10 \mathrm{~m}$, all models behaved similarly. Above $10 \mathrm{~m}$, we observed similar models for SI 6, 8, and 11, and for SI 14, 17, 20, and 23. Given h95_first, the model for SI 23 appeared more similar to the models for SI 14 and 17 than to the models for SI 20 and 26. The models, however, contained more predictors whose influence is not considered in Fig. 4.

We applied the SI-specific models to the NFI data using the SI map (pSI) to get accuracy metrics, which are more realistic for a practical application where only pSI is available. Because pSI did not contain predictions of 6 and 26, models for these SI categories were never used. RMSE ranged from 18.6 to 56.0 years $(29.4 \%$ to 53.2\%), and MD from 5.4 to 37.2 years (5.3\% to $31.2 \%$ ). Average RMSE and MD for all pSI categories were 41.1 years (48.8\%) and 20.6 years (24.5\%), respectively (Table 3, for pine and birch see Additional file 1: Table S2). Except for pSI 8, RMSE and MD decreased with increasing pSI (Table 3). Age predictions for sample plots with SI corresponding to pSI follow the 1:1 line well, whereas plots with disagreement between observed SI and pSI showed systematic lack-of-fit (Fig. 5). This trend was most obvious for pSI 11 to 20. If pSI was larger than SI, the predicted age was too small (positive residual), whereas the opposite was observed if pSI was larger than SI.

In the same way as for pSI, we used mapped tree species for applying the SI-specific models to the NFI data to get accuracy metrics, which are more realistic for a practical application where only a tree species map is available. To isolate the effect of predicted tree species from the pSI effect, we used observed SI for this analysis. RMSE ranged from 3 to 32 years (7\% to 25\%), and MD from -4 to 2 years ( $-4 \%$ to $2 \%$ ). Average RMSE and MD for all SI categories were 21 years (25\%) and 0 years, respectively (Table 4, for pine and birch see Additional 

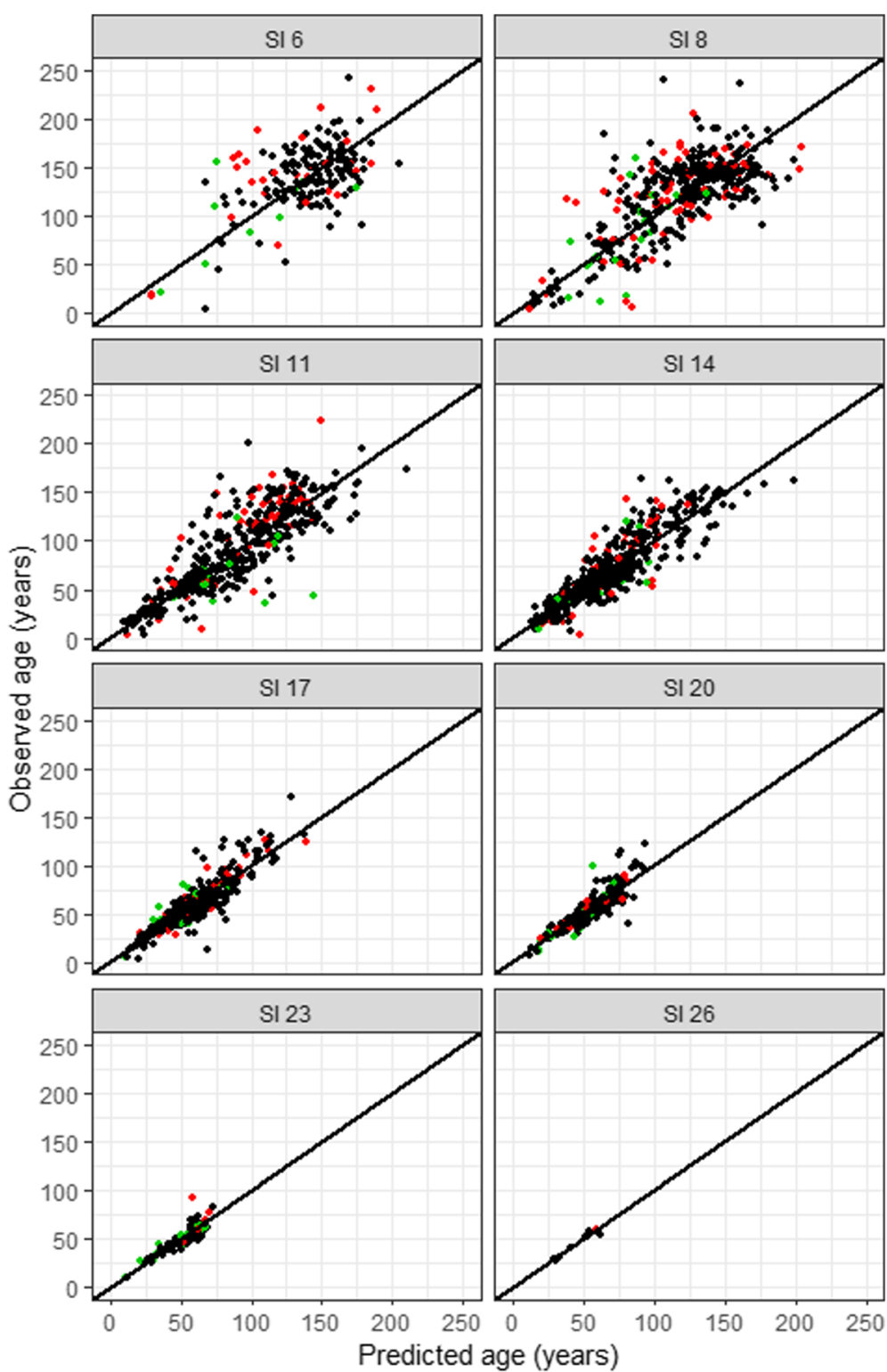

Predicted tree species

spruce

pine

birch

Fig. 3 Observed versus predicted age (years) in spruce forest for the eight site-index (SI) specific models with predictors from remotely sensed data; predicted tree species are presented in color

Table 2 Characteristics of the fitted models for spruce. (SI: site index)

\begin{tabular}{llllllllll}
\hline & SI $\mathbf{6}$ & SI $\mathbf{8}$ & SI $\mathbf{1 1}$ & SI $\mathbf{1 4}$ & SI 17 & SI 20 & SI 23 & SI 26 & All SI \\
\hline Norway spruce & & & & & & & & & \\
$R^{2}$ & 0.46 & 0.60 & 0.75 & 0.79 & 0.79 & 0.84 & 0.91 & 0.96 \\
RMSE (Years) & 30.5 & 31.2 & 23.3 & 15.4 & 10.8 & 9.3 & 7.0 & 2.9 \\
RMSE (\%) & 21.8 & 25.8 & 25.5 & 22.8 & 18.6 & 17.5 & 14.2 & 6.4 & 21.2 \\
MD (Years) & 2.1 & 2.6 & 1.8 & 0.5 & -0.2 & -0.4 & -0.7 & -1.0 & 1.0 \\
MD (\%) & 1.5 & 2.2 & 1.9 & 0.8 & -0.3 & -0.8 & -1.5 & -2.2 & 1.2 \\
\hline
\end{tabular}




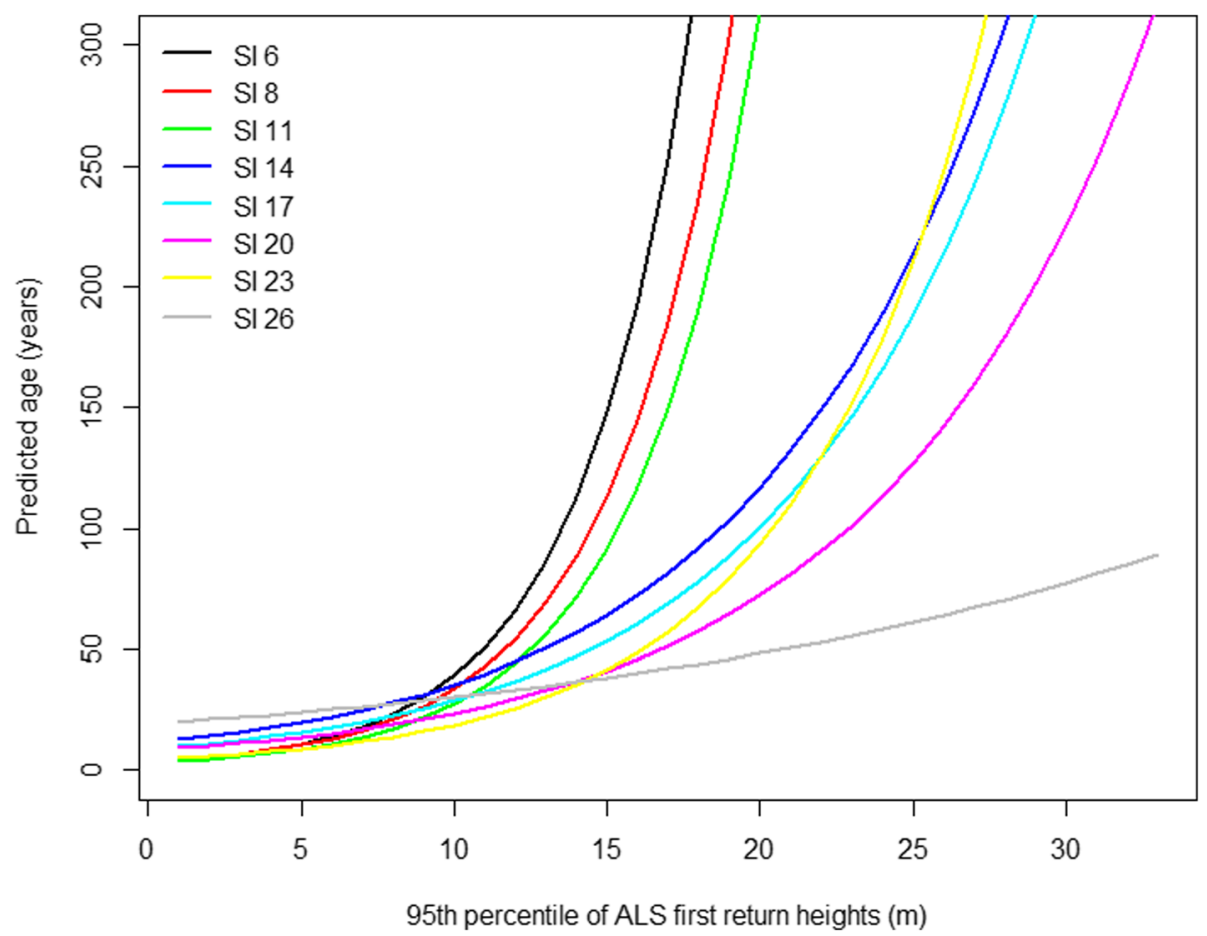

Fig. 4 Predicted age (years) over the 95th percentile of first returns ALS heights (h95_first) ranging from 0 to 32, and all other predictors set to their mean values for spruce models

file 1: Table S3). RMSE decreased with increasing SI; however, there was no clear trend for RMSE\% and MD\%. Age predictions for sample plots with predicted tree species corresponding to the tree species specific model followed the 1:1 line well, whereas plots with disagreement between observed and predicted tree species often showed lack-of-fit. This trend was most obvious for pine and birch. Overall, less variability was introduced by the tree species predictions compared to pSI.

\section{Validation with independent field data}

The estimated stand age of the validation stands resulted in area-weighted RMSE of 11.5 years (21.6\%), and MD of 1.6 years $(3.0 \%)$. The RMSE decreased with increasing $\mathrm{pSI}$ (Table 5). MD was large and negative for pSI 11, and large and positive for pSI 20. This is also reflected in the

Table 3 Root mean squared error (RMSE), RMSE\%, mean deviance (MD), and MD\% of the site index (SI) specific models applied using the predicted site index (pSI)

\begin{tabular}{|c|c|c|c|c|c|c|c|}
\hline & pSI 8 & pSI 11 & pSI 14 & pSI 17 & pSI 20 & pSI 23 & All pSI \\
\hline \multicolumn{8}{|c|}{ Norway spruce } \\
\hline RMSE & 34.4 & 56.0 & 47.8 & 28.8 & 22.6 & 18.6 & 41.1 \\
\hline RMSE (\%) & 29.4 & 47.0 & 53.2 & 42.2 & 39.0 & 32.5 & 48.8 \\
\hline MD & 6.2 & 37.2 & 25.5 & 12.2 & 8.8 & 5.4 & 20.6 \\
\hline MD (\%) & 5.3 & 31.2 & 28.4 & 18.0 & 15.2 & 9.4 & 24.5 \\
\hline
\end{tabular}

graphical representation of the results (Fig. 6). For estimated pSI 11, stand ages were estimated with too large values; one stand in particular with observed SI "Medium" was heavily overestimated. For estimated pSI 20, all stands with observed SI "Medium" were underestimated.

Figure 7 provides an impression of the age map in comparison to an aerial image for two validation stands. Observed stand ages were 52 and 72 years, and site index of the stands was "Medium". Estimated stand age was 50 and 82 years and the estimated site index was 14 and 17 for the two stands, respectively.

\section{Discussion}

We mapped forest stand age using a combination of ALS and Sentinel-2 based variables over a large study area in Norway encompassing various growing conditions. We used more than 4800 NFI sample plots with stand ages ranging from 3 to over 280 years and fitted SI-specific models that were validated on stand level using independent data. We found that forest age can be predicted with relatively high accuracy, especially for forests younger than 100 years and that tree height estimated from airborne laser scanning and predicted site index were the most important variables in predicting age. While the main manuscript only describes the results for spruce forests, the Additional file 1 provides similar results for pine and broadleaved (birch) 

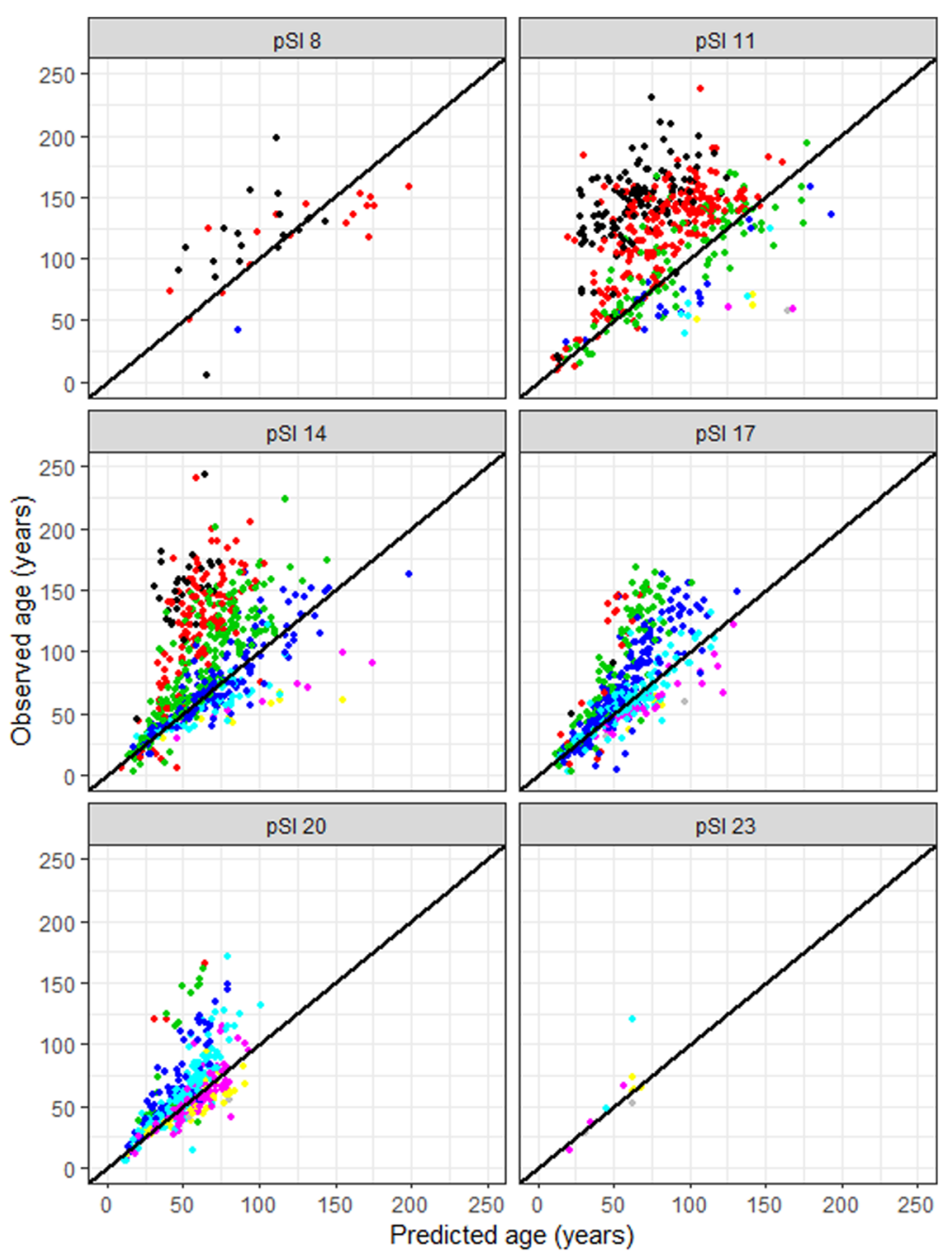

Observed site index

- $6 \cdot 11 \cdot 17 \cdot 23$

- $8 \cdot 14 \cdot 20 \cdot 26$

Fig. 5 Observed versus predicted age for the models applied to the six classes of predicted site index (pSI) for spruce (for pine and birch see Additional file 1)

dominated forests. In order to apply the proposed modelling approach, site index and tree species maps are required as input variables. Errors in these maps introduced errors in the prediction of age. With improved maps of tree species and site index, our results will improve as well, especially for forest stands above 100 years of age.

We obtained the best results with SI-specific models, which showed that SI was a critical variable for describing age. We observed that the age predictions corresponded

Table 4 Root mean squared error (RMSE), RMSE\%, mean deviance (MD), and MD\% of the site index (SI) specific models applied using the predicted tree species Norway spruce

\begin{tabular}{llllllllll}
\hline & SI $\mathbf{6}$ & SI $\mathbf{8}$ & SI $\mathbf{1 1}$ & SI 14 & SI 17 & SI 20 & SI 23 & SI 26 & All SI \\
\hline Norway spruce & & & & & & & & & \\
RMSE & 32.4 & 29.9 & 23.1 & 15.3 & 10.9 & 10.8 & 7.1 & 3.0 & 21.3 \\
RMSE (\%) & 23.6 & 24.9 & 26.0 & 22.9 & 19.1 & 20.1 & 15.4 & 7.0 & 25.4 \\
MD & -4.1 & 1.8 & 0.3 & -0.3 & -0.8 & -0.3 & -1.7 & -1.0 & -0.2 \\
MD (\%) & -3.0 & 1.5 & 0.4 & -0.4 & -1.5 & -0.6 & -3.7 & -2.3 & -0.2 \\
\hline
\end{tabular}


Table 5 Area-weighted root mean squared error (RMSE) and area weighted mean deviance (MD) separately for estimated site index (pSI) classes in 63 validation stands

\begin{tabular}{llllll}
\hline & pSI 11 & pSI 14 & pSI 17 & pSI 20 & All pSI \\
\hline RMSE & 25.7 & 12.9 & 9.0 & 8.6 & 11.5 \\
RMSE (\%) & 48.4 & 24.4 & 16.9 & 16.2 & 21.6 \\
MD & -23.1 & 2.8 & 1.9 & 6.6 & 1.6 \\
MD (\%) & -39.0 & 5.1 & 3.8 & 11.6 & 3.0 \\
\hline
\end{tabular}

well with the reference age where observed and predicted site index agree. However, plots with observed SI lower than pSI were underpredicted, whereas plots with observed SI larger than pSI were overpredicted. Besides uncertainties in the models, this can be explained by the fact that trees on higher SI grow faster and therefore are taller at a given age. In the opposite case, if the actual SI is smaller than the predicted SI, age at a given height is underpredicted because trees grow slower than expected. While using the mapped instead of the observed tree species hardly changed the RMSE, a 100\% increase in RMSE was observed when using the mapped instead of the observed SI. This underlines the importance of an accurate site index map for using the proposed modelling approach to obtain an age map with relatively high accuracy. Nonetheless, the quality of the SI map was sufficient for obtaining reasonably good results (RMSE of 11.5 years) of stand age estimates for validation stands although errors in the SI map were noticeable also on stand level. The limitations of the dependence on SI are that SI can change, for example due to disturbances, fertilization, or other management activities, and its meaningfulness may be limited in mixed-species stands or on organic soils. However, these uncertainties are reflected in our models, at least partially, because SI was used to fit stratified models and the aforementioned limitations caused uncertainties that are inherent to the models and documented in this study.

Sentinel-2 bands or NDVI were included in 11 of the 22 models as predictor variables. However, the contribution of these predictors was relatively small compared to the predictor h95_first. This was evaluated by fitting the models with standardized data (centered around their mean and scaled by dividing by their standard deviation). While the standardized variable h95_first was the most important predictor in all models with the largest parameter estimates, the Sentinel-2 based predictors and the other variables contributed only very little to the models.

Other studies in boreal and temperate forests modelling forest age obtained comparable results, even though they were conducted on smaller study sites. Racine et al. (2014) used a kNN approach and reported RMSE from leave-one-out cross-validation of 8.8 years $(19 \%)$ for a

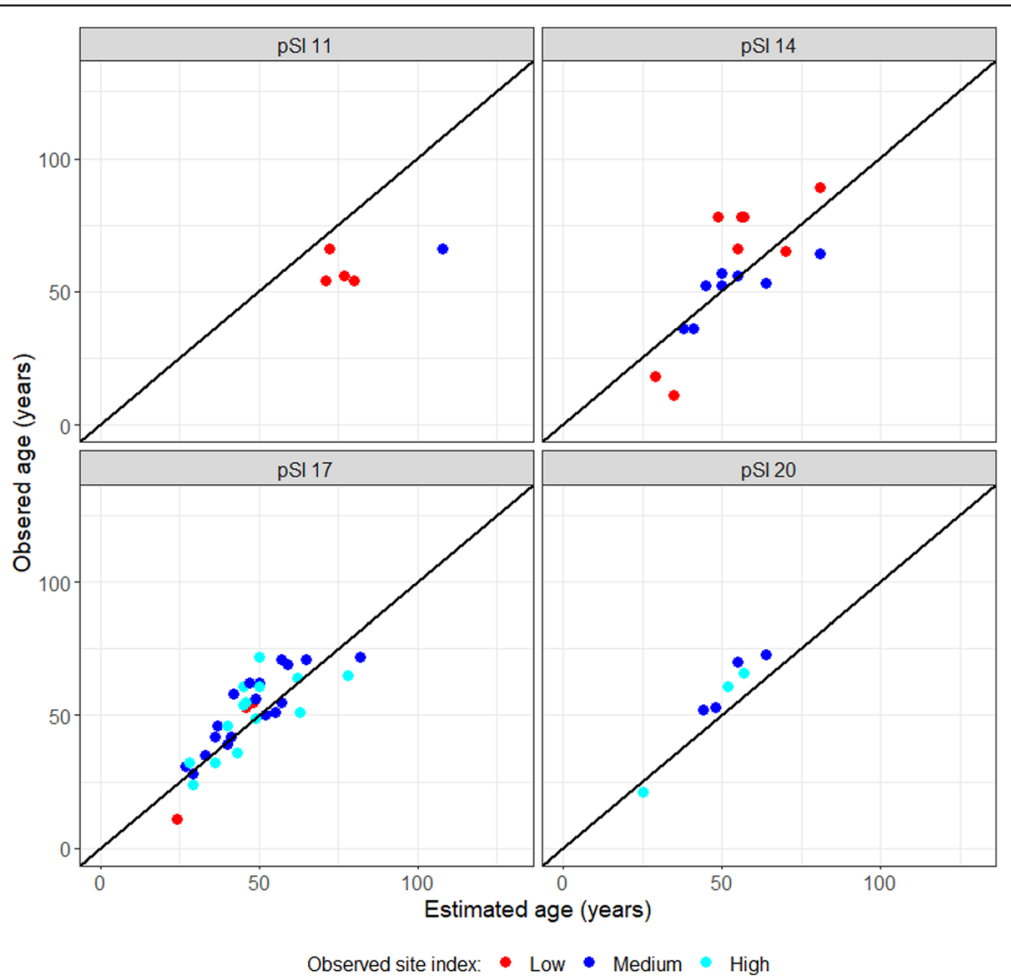

Fig. 6 Observed and estimated stand age in validation stands by estimated site indices (pSI); the observed site index (SI) on stand level was recorded as "Low", "Medium", and "High", which are presented in color 

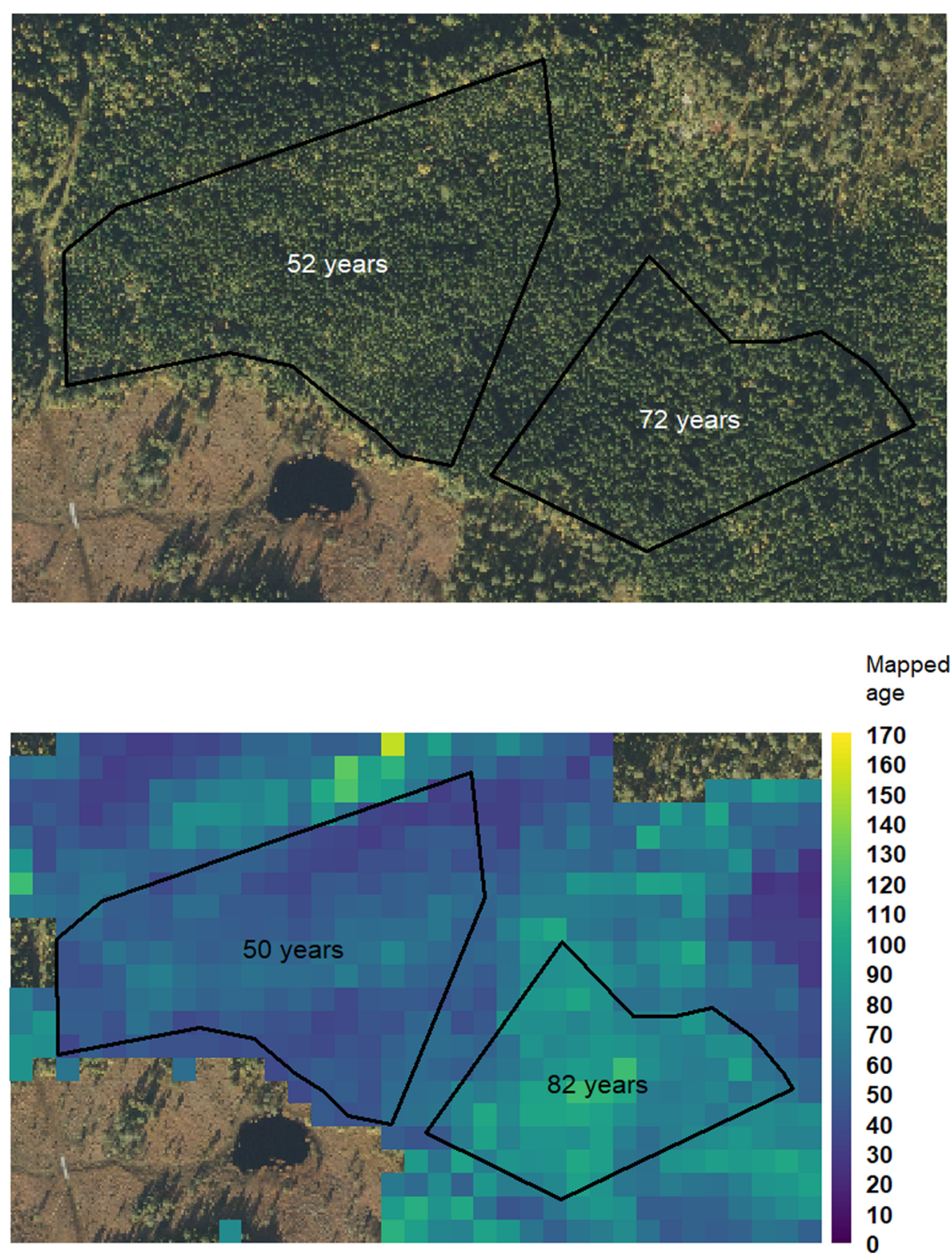

Fig. 7 Above: Outline of validation stands with known age (RGB image in background). Below: Mapped and estimated age for the same stands

$66 \mathrm{~km}^{2}$ study site with 158 sample plots in Canada, where mean reference age ranged from 11 to 94 years. Maltamo et al. (2009) also used a kNN approach and reported RMSE of 18.8 years (88\%) for spruce, 23.5 years $(51 \%)$ for pine, and 18.7 years $(102 \%)$ for deciduous dominated sample plots in Finland, where reference age ranged from 0 to 150 years. In total they used $335 \mathrm{NFI}$ sample plots in a 22,000 ha study site for modelling. A study in temperate forests was conducted by Straub and Koch (2011) who used both airborne ALS and multispectral variables to model forest stand age in a small study area covering $9.2 \mathrm{~km}^{2}$, with 108 forest stands and 300 inventory sample plots in south-west Germany using linear regression. Forest age ranged from 0 to 153 years, and the forest area was composed of various deciduous and coniferous tree species. They reported an $\mathrm{R}^{2}$ of 0.63 , and RMSE of 19.7 years (29\%). We obtained RMSE between 21 and 25 years (23\% to $29 \%$ ) for more than 4800 NFI sample plots with age ranging from 3 to over 280 years. However, our study represents with 18.2 Mha a much larger area, encompassing a wide range of growing conditions and forest structures. Our models can, therefore, be applied for practical forest management throughout the study area corresponding to the majority of the productive forests in Norway. 
In the study by Maltamo et al. (2009), 69 independent validation stands with an average area of 1 ha and age ranging from 0 to 126 years were used, resulting in stand level RMSE of 18.3 years (36\%) for spruce. In a Mediterranean to temperate climate in central Italy, Frate et al. (2015) obtained RMSE of 16 years (30\%) using 305 independent validation stands with stand age ranging from 1 to 127 years and mean of 52 years. Our results on 63 independent validation stands were comparable with RMSE of 11.5 (22\%). The smaller errors in our study might be related to younger stands ranging from 11 to 89 years, and the better performance of our models in younger forest stands compared to older ones.

Maltamo et al. (2020) reported for forest stands younger than 100 years a RMSE of 14 years. Our overall result for spruce with age up to 270 years was a RMSE of 21 years. As results for the independent validation stands with age up to 89 years showed, our models performed well for stands younger than 100 years of age. In an initial analysis, a model fitted with data using only NFI plots in spruce stands younger than 100 years (model not presented) resulted in smaller errors with RMSE and MD of 12.7 and 1.6 years, respectively, which fits with the results of Maltamo et al. (2020). However, 36\% of the NFI plots in the productive managed forest are older than 100 years, and predictions for those stands would have resulted in severe underestimates. It was also not possible to find a satisfying model distinguishing forest older than 100 years from younger forest.

\section{Conclusions}

The age of spruce, pine and broadleaved (birch) dominated forest stands was mapped on a fine scale $(16 \mathrm{~m} \times$ $16 \mathrm{~m}$ ) for a large study area using variables from remotely sensed data and SI-specific models. Tree height estimated from airborne laser scanning and predicted site index were the most important variables in the models describing age. Errors decreased with increasing site index. Improved site index maps would be the single most important measure to improve the age prediction. The contribution of optical Sentinel-2 data was limited for forest age modelling in this study. However, the synergy of optical and 3D remote sensing data provides great opportunities to map various forest attributes in general. Stratification by tree species improves predictions of forest attributes relying on 3D remote sensing data in many cases. In the present study we relied on tree species information that was classified and mapped using optical satellite data. High-quality ground reference data are key in most remote sensing based studies modelling forest attributes. Also this study profited from the precise geo-location of field plots and accurate data collection of tree and stand properties that result from the Norwegian NFI system.

\section{Supplementary Information}

The online version contains supplementary material available at https://doi. org/10.1186/s40663-020-00274-9.

\begin{abstract}
Additional file 1: Table S1. Characteristics of the fitted models for pine and birch (SI: site index). Figure S1. Observed versus predicted age (years) for the eight site index (SI) specific models with predictors from remotely sensed data for pine; predicted tree species in colour. Figure S2. Observed versus predicted age (years) for the eight site index (SI) specific models with predictors from remotely sensed data for birch; predicted tree species in colour. Figure S3. Predicted age (years) over the 95th percentile of first returns ALS heights (h95_first) ranging from 0 to 32 , and all other predictors set to their mean values for pine models. Figure S4. Predicted age (years) over the 95th percentile of first returns ALS heights (h95_first) ranging from 0 to 32, and all other predictors set to their mean values for birch models. Table S2. Root mean squared error (RMSE), RMSE\%, and mean deviance (MD) of the site index (SI) specific models applied using the predicted site index (pSI) for pine and birch. Figure S5. Observed versus predicted age for the models applied to the six classes of predicted site index (pSI) for pine. Figure S6.

Observed versus predicted age for the models applied to the six classes of predicted site index (pSI) for birch. Table S3. Root mean squared error (RMSE), RMSE\%, mean deviance (MD), and MD\% of the site index (SI) specific models applied using the predicted tree species pine and birch. Table S4. Models for spruce; coefficients, their standard errors, t- and $p$ values for the site index (SI) specific linear regression models. Table S5. Models for pine; coefficients, their standard errors, t- and p-values for the site index (SI) specific linear regression models. Table S6. Models for birch; coefficients, their standard errors, t- and p-values for the site index (SI) specific linear regression models.
\end{abstract}

\section{Abbreviations}

NFI: National Forest Inventory; ALS: Airborne Laser Scanning; SI: Site index; pSI: Predicted site index; RMSE: Root Mean Squared Error; MD: Mean deviance; asl: Above sea level; kNN: k-nearest neighbour; dbh: Diameter at breast height; GNSS: Global navigation satellite system; DTM: Digital terrain model; S2: Sentinel-2; BOA: Bottom of atmosphere; NIR: Near infra-red; SWIR: Short wave infra-red; NDVI: Normalized Difference Vegetation Index; AIC: Akaike's Information Criterion

\section{Acknowledgements}

We would like to thank the County Governor (Fylkesmann) in Trøndelag, represented by Arne Rannem, for providing the forest stands used for validation. We would like to thank Ferdinand Klingenberg of the Norwegian Mapping Agency for the provision of the Sentinel 2 mosaic, and two anonymous reviewers for valuable comments and suggestions. The document was language edited by Nicholas Clarke.

\section{Authors' contributions}

J.S., M.H., R.A and J.B. conceived and designed the study; J.S., and J.B. analyzed the data; J.S., M.H., R.A. and J.B. wrote the paper. All the authors read and approved the final manuscript.

\section{Funding}

This study was supported by the Norwegian Institute of Bioeconomy Research.

\section{Availability of data and materials}

Nationwide datasets are available online under:

https://kilden.nibio.no/?lang $=n b \& X=7195706.12 \& Y=284337.75 \& z 0 o m=0$ 051591704779414\&topic=arealinformasjon\&bgLayer=graatone_cache The datasets used and/or analyzed during the current study are available from the corresponding author on reasonable request; however, information on NFI plot location cannot be provided.

Ethics approval and consent to participate Not applicable.

Consent for publication

Not applicable. 


\section{Competing interests}

The authors declare that they have no competing interests.

Received: 26 April 2020 Accepted: 23 October 2020

Published online: 10 November 2020

\section{References}

Antón-Fernández C, Mola-Yudego B, Dalsgaard L, Astrup R (2016) Climatesensitive site index models for Norway. Can J For Res 46:794-803. https://doi. org/10.1139/cjfr-2015-0155

Astrup R, Rahlf J, Bjørkelo K, Debella-Gilo M, Gjertsen A, Breidenbach J (2019) Forest information at multiple scales: development, evaluation and application of the Norwegian forest resources map SR16. Scand J For Res 0: 1-13. https://doi.org/10.1080/02827581.2019.1588989

Breidenbach J, Granhus A, Hylen G, Eriksen R, Astrup R (2020a) A century of National Forest Inventory in Norway - informing past, present, and future decisions. For Ecosyst 7. https://doi.org/10.1186/s40663-020-00261-0

Breidenbach J, Waser LT, Debella-Gilo M, et al (2020b) National mapping and estimation of forest area by dominant tree species using Sentinel-2 data. Can J For Res 0(ja). https://doi.org/10.1139/cjfr-2020-0170

Buddenbaum H, Schlerf M, Hill J (2005) Classification of coniferous tree species and age classes using hyperspectral data and geostatistical methods. Int J Remote Sens 26:5453-5465. https://doi.org/10.1080/01431160500285076

Chirici G, Winter S, McRoberts RE (eds) (2011) National Forest Inventories: contributions to Forest biodiversity assessments. Managing Forest ecosystems, 1st edn. Springer, Netherlands

Core Team R (2019) R: a language and environment for statistical computing. R Foundation for Statistical Computing, Vienna, Austria

Drusch M, Del Bello U, Carlier S, Colin O, Fernandez V, Gascon F, Hoersch B, Isola C, Laberinti P, Martimort P, Meygret A, Spoto F, Sy O, Marchese F, Bargellini P (2012) Sentinel-2: ESA's optical high-resolution Mission for GMES operational services. Remote Sens Environ 120:25-36. https://doi.org/10.1016/j.rse.2011. 11.026

Dye M, Mutanga O, Ismail R (2012) Combining spectral and textural remote sensing variables using random forests: predicting the age of Pinus patula forests in KwaZulu-Natal, South Africa. J Spat Sci 57:193-211. https://doi.org/ $10.1080 / 14498596.2012 .733620$

Frate L, Carranza ML, Garfi V, Di Febbraro M, Tonti D, Marchetti M, Ottaviano M, Santopuoli G, Chirici G (2015) Spatially explicit estimation of forest age by integrating remotely sensed data and inverse yield modeling techniques. iForest - biogeosciences for 9:63. https://doi.org/10.3832/IFOR1529-008

Grissino-Mayer H (2003) A manual and tutorial for the proper use of an increment borer. Tree-ring Res 59:63-79

Guo X, Coops NC, Tompalski P, Nielsen SE, Bater CW, Stadt JJ (2017) Regional mapping of vegetation structure for biodiversity monitoring using airborne lidar data. Ecol Inform 38:50-61. https://doi.org/10.1016/j.ecoinf.2017.01.005

Hudak AT, Tod Haren A, Crookston NL, Liebermann RJ, Ohmann JL (2014) Imputing forest structure attributes from stand inventory and remotely sensed data in western Oregon, USA. For Sci 60:253-269. https://doi.org/10. 5849/forsci.12-101

Jensen JR, Qiu F, Minhe J (1999) Predictive modelling of coniferous forest age using statistical and artificial neural network approaches applied to remote sensor data. Int J Remote Sens 20:2805-2822. https://doi.org/10.1080/ 014311699211804

Kandare K, Ørka HO, Dalponte M, Næsset E, Gobakken T (2017) Individual tree crown approach for predicting site index in boreal forests using airborne laser scanning and hyperspectral data. Int J Appl Earth Obs Geoinf 60:72-82. https://doi.org/10.1016/J.JAG.2017.04.008

Kartverket (2019) Høydedata og terrengmodeller for landområdene. https://www. kartverket.no/data/Hoydedata-og-terrengmodeller/. Accessed 11 Mar 2020

Kayitakire F, Hamel C, Defourny P (2006) Retrieving forest structure variables based on image texture analysis and IKONOS-2 imagery. Remote Sens Environ 102:390-401. https://doi.org/10.1016/j.rse.2006.02.022

Lang N, Schindler K, Wegner JD (2019) Country-wide high-resolution vegetation height mapping with Sentinel-2. Remote Sens Environ. https://doi.org/10. 1016/j.rse.2019.111347

Maltamo M, Kinnunen $H$, Kangas A, Korhonen $L$ (2020) Predicting stand age in managed forests using National Forest Inventory field data and airborne laser scanning. For Ecosyst 7. https://doi.org/10.1186/s40663-020-00254-Z

Maltamo M, Packalén P, Suvanto A, Korhonen KT, Mehtatalo L, Hyvonen P (2009) Combining ALS and NFI training data for forest management planning: a case study in Kuortane, Western Finland. Eur J For Res 128:305-317. https:// doi.org/10.1007/s10342-009-0266-6

Mora B, Wulder MA, Hobart GW, White JC, Bater CW, Gougeon FA, Varhola A, Coops NC (2013) Forest inventory stand height estimates from very high spatial resolution satellite imagery calibrated with lidar plots. Int J Remote Sens 34:4406-4424. https://doi.org/10.1080/01431161.2013.779041

Mura M, McRoberts RE, Chirici G, Marchetti M (2015) Estimating and mapping forest structural diversity using airborne laser scanning data. Remote Sens Environ 170:133-142. https://doi.org/10.1016/j.rse.2015.09.016

Næsset E (1997) Determination of mean tree height of forest stands using airborne laser scanner data. ISPRS J Photogramm Remote Sens 52:49-56

Næsset E (2002) Predicting forest stand characteristics with airborne scanning laser using a practical two-stage procedure and field data. Remote Sens Environ 80:88-99. https://doi.org/10.1016/S0034-4257(01)00290-5

Nord-Larsen T, Riis-Nielsen T (2010) Developing an airborne laser scanning dominant height model from a countrywide scanning survey and national forest inventory data. Scand J For Res 25:262-272. https://doi.org/10.1080/ 02827581.2010 .486000

Norwegian Institute of Bioeconomy Research (2020) Kilden. https://kilden.nibio. no/?lang=nb\&topic $=$ arealinformasjon $\& X=6806335.39 \& Y=156107.84 \& z o o m=2$. 0587521207172212\&bgLayer=graatone_cache\&catalogNodes $=102,402,816$ \&layers=skogressurs gran_r\&layers_opacity $=0.75$. Accessed 28 Feb 2020

Nothdurft A, Wolf T, Ringeler A, Bohner J, Saborowski J (2012) Spatio-temporal prediction of site index based on forest inventories and climate change scenarios. For Ecol Manag 279:97-111. https://doi.org/10.1016/j.foreco.2012.05.018

Puliti S, Hauglin M, Breidenbach J, Montesano P, Neigh CSR, Rahlf J, Solberg S, Klingenberg TF, Astrup R (2020) Modelling above-ground biomass stock over Norway using national forest inventory data with ArcticDEM and Sentinel-2 data. Remote Sens Environ 236:111501. https://doi.org/10.1016/J.RSE.2019. 111501

Racine EB, Coops NC, St-Onge B, Begin J (2014) Estimating forest stand age from LiDAR-derived predictors and nearest neighbor imputation. For Sci 60:128136. https://doi.org/10.5849/forsci.12-088

Reese H, Nilsson M, Pahén TG, Hagner O, Joyce S, Tingelof U, Egberth M, Olsson $\mathrm{H}$ (2003) Countrywide estimates of forest variables using satellite data and field data from the National Forest Inventory. Ambio 32:542-548

Sharma RP, Brunner A, Eid T (2012) Site index prediction from site and climate variables for Norway spruce and scots pine in Norway. Scand J For Res 27: 619-636. https://doi.org/10.1080/02827581.2012.685749

Skovsgaard JP, Vanclay JK (2008) Forest site productivity: a review of the evolution of dendrometric concepts for even-aged stands. Forestry 81:13-31. https://doi.org/10.1093/forestry/cpm041

Socha J, Pierzchalski M, Bałazy R, Ciesielski M (2017) Modelling top height growth and site index using repeated laser scanning data. For Ecol Manag. https:// doi.org/10.1016/j.foreco.2017.09.039

Straub C, Koch B (2011) Enhancement of bioenergy estimations within forests using airborne laser scanning and multispectral line scanner data. Biomass Bioenergy 35:3561-3574. https://doi.org/10.1016/j.biombioe.2011.05.017

Tveite B (1977) Foreløpige retningslinjer for bonitering etter nytt bonitetssystem. Avdeling for Skogbehandling og Skogproduksjon, rapport 4/77

Zhang C, Ju W, Chen JM, Li D, Wang X, Fan W, Li M, Zan M (2014) Mapping forest stand age in China using remotely sensed forest height and observation data. J Geophys Res Biogeosci 119:1163-1179. https://doi.org/10. 1002/2013JG002515

\section{Submit your manuscript to a SpringerOpen ${ }^{\circ}$ journal and benefit from:}

- Convenient online submission

- Rigorous peer review

- Open access: articles freely available online

- High visibility within the field

- Retaining the copyright to your article

Submit your next manuscript at $>$ springeropen.com 